\title{
Recurrent Kaposi Sarcoma
}

National Cancer Institute

\section{Source}

National Cancer Institute. Recurrent Kaposi Sarcoma. NCI Thesaurus. Code C7935.

The reemergence of Kaposi sarcoma after a period of remission. 